\title{
Development and Characterization of Surface Porosity in Tannery Sludge Derived Adsorbent
}

\section{Geethakarthi A*}

Department of Civil Engineering, Kumaraguru College of Technology, Coimbatore, Tamil Nadu, India

\begin{abstract}
In this work, activated carbons were prepared by a combination of physical and chemical activation from raw tannery sludge. The burn-off and the yield percentage of the acid activated carbons were evaluated for two particle size namely $600 \mu \mathrm{m}$ (TSC600) and $300 \mu \mathrm{m}$ (TSC300). The developed activated carbons were characterized and analysed for adsorption isotherm under nitrogen atmosphere at $-196.86^{\circ} \mathrm{C}$. The Scanning Electron Microscopy (SEM), Thermo Gravimetric Analysis (TGA) and the functional groups were also identified for the tannery sludge activated carbons. The thermal stability for the activated carbons TSC600 and TSC300 were confirmed by their exothermic peaks at $971.1^{\circ} \mathrm{C}$ and $897.4^{\circ} \mathrm{C}$ respectively. The higher surface area of the sludge carbons was obtained by the BET isotherm plot, suggesting the application of the produced carbon as a potential adsorbent. The surface area of TSC600 and TSC300 at the activating condition was $188.205 \mathrm{~m}^{2} / \mathrm{g}$ and $212.32 \mathrm{~m}^{2} / \mathrm{g}$. The pore size distribution of the sludge developed was obtained by BET isotherm under the BJH method $\left(19.77 \mathrm{~A}^{\circ}<200 \mathrm{~A}^{\circ}\right)$ and HK method $\left(5.25 \mathrm{~A}^{\circ}<200 \mathrm{~A}^{\circ}\right)$. The developed carbons were dominated by micropores and mesopores.
\end{abstract}

Keywords: Activation; Tannery sludge; SEM images; Yield percentage; Nitrogen isotherm; Micro pores

\section{Introduction}

Adsorption is an efficient method for the removal of dyes from wastewater and activated carbon is one of the most studied adsorptive materials [1-4]. The adsorption capacity depends on the textural properties of the carbons such as porosity, surface area, nature of the adsorbate and the adsorbate concentration [5,6]. The surface characteristics and the internal pore structure of the activated carbon play an important role in adsorption processes. These parameters depend on both, the precursor used and the method of preparation. Therefore, an adequate characterization of the adsorbent is crucial to the adsorption and separation processes. Recently, the surface chemistry of activated carbons is focused to interpret results of dye adsorption experiments [7] The use of activated carbons derived from expensive starting materials is not satisfactory for most pollution control applications. Research works on the usage of non-conventional adsorbents (natural materials, bio sorbents and waste materials from industry and agriculture) with lower cost and high efficiency [8-10] are being focussed. Several recent publications [11-13] indicate the interest in developing sustainable and environmentally safe recycling processes to produce value products such as activated carbon from wastes. The activation of carbon can be carried out by chemical or physical means. In this work, the development of tannery sludge carbon by acid activation combined with pyrolysis is carried out. The characterisation of the activated sludge carbon is supported by various analytical methods.

\section{Experimental}

\section{Materials}

Preliminary tannery sludge was collected from a common tannery effluent treatment plant, Ranipet, India. The chemical reagents used for the analysis of the activated carbon samples were of AR grade. Deionised water was used in preparing solutions throughout the investigations.

\section{Preparation of activated carbon}

The dried tannery raw sludge was sieved to a particle size of 600 $\mu \mathrm{m}$ (TSC600) and $300 \mu \mathrm{m}$ (TSC300). The sieved sludge particles were subjected to a combination of chemical and physical activation. Chemical activation was done by immersing the dried sludge in 5:1 sulphuric acid for an impregnation period of 12 hours with the impregnation ratio
2. The chemically activated samples were washed several times with deionised water to remove the effect of excess acid and dried in oven for 4 hours. The dried sample after desiccation was used for the activation in a horizontal tubular furnace for pyrolysis in the presence of nitrogen atmosphere at $650^{\circ} \mathrm{C}$ for 3 hours. These activated sludge carbons were used for the further analysis.

\section{Analytical methods}

Instrumental analysis: Netzsch STA 409 (Simultaneous Thermal Analyzer) was used for the simultaneous measurements of TG-DTA (Thermogravimetric-Differential Thermal Analyser). The temperature of $\mathrm{SiC}$ furnace ranged from room temperature to $1600^{\circ} \mathrm{C}$. The heating rate of the sludge sample/activated carbon was maintained at $10^{\circ} \mathrm{C} / \mathrm{min}$ in an inert nitrogen atmosphere with a flow rate of $100 \mathrm{~mL} / \mathrm{min}$. The SEM analysis was carried out using JEOL JSM-6360 scanning electron microscope. The resolution of the microscope was $4.0 \mathrm{~nm}$ with an accelerating voltage of 0.5 to $30 \mathrm{keV}$. The magnification of the instrument was from 50X to 10000X. ASAP 2020 (Micromeritics) was used for the specific surface area analysis, pore volume and pore size distribution of the sludge sample/carbons using multipoint adsorption in the $\mathrm{P} / \mathrm{P}_{0}$ range 0.05 to $0.33, \mathrm{~N} 2$ isotherms at $77 \mathrm{~K}$ and Brunauer Emmett and Teller Equation. Barrett, Joyner and Halenda (BJH) method and the Horvath-Kawazoe (HK) method are the simple and popular methods used for the evaluating pore size distrubution of the mesoporous and microporous adsorbents. The $\mathrm{pH}$ of the sample was measured in a digital $\mathrm{pH}$ meter model $111 \mathrm{E} / 01 \mathrm{E}$ with resolution $0.01 \mathrm{pH} ; 1 \mathrm{mV}$ and an accuracy of $\mathrm{pH} \pm 0.01$.

Boehm titration: Procedures for the analysis of oxygen functional group for the activated carbons TSC600 and TSC300 were estimated

*Corresponding author: Geethakarthi A, Department of Civil Engineering Kumaraguru College of Technology, Coimbatore, Tamil Nadu, India, Tel: + 91 9443452576; E-mail: ageethakarthi@yahoo.com

Received May 30, 2017; Accepted August 24, 2017; Published August 29, 2017

Citation: Geethakarthi A (2017) Development and Characterization of Surface Porosity in Tannery Sludge Derived Adsorbent. J Civil Environ Eng 7: 281. doi: 10.4172/2165-784X.1000281

Copyright: $\odot 2017$ Geethakarthi A. This is an open-access article distributed under the terms of the Creative Commons Attribution License, which permits unrestricted use, distribution, and reproduction in any medium, provided the original author and source are credited. 
by Boehm [14]. Activated carbon samples were placed in an oven and dried at $105^{\circ} \mathrm{C}$ for 24 hours. $25 \mathrm{~mL}$ of an alkali solution $\left(0.25 \mathrm{~N} \mathrm{NaHCO}_{3}\right.$, $\mathrm{Na}_{2} \mathrm{CO}_{3}$, and $\mathrm{NaOH}$ ) was added in Erlenmeyer flasks containing a given amount of activated carbon samples ( $1 \mathrm{~g}$ ). The samples were constantly mixed in an orbital shaker at $25^{\circ} \mathrm{C}$ for 24 hours. $5 \mathrm{~mL}$ of the mixed sample were filtered and back titrated with $0.25 \mathrm{~N} \mathrm{HCl}$ solution. The concentration of various functional groups was calculated by measured residual bases.

\section{Results and Discussion}

\section{Characterization of tannery sludge activated carbon}

The developed tannery sludge carbons TSC600 and TSC300 were characterized for its proximate and ultimate analysis. The burn-off percentage and yield percentage of the sludge carbon samples were also analyzed. The characterization of the sludge activated carbons are shown in Table 1.

\section{Analytical methods}

Thermal analysis: TG-DTG spectrum of the sludge carbons are illustrated in Figures 1 and 2. The initial weight loss observed was due to

\begin{tabular}{|c|c|c|c|c|c|c|c|c|c|}
\hline \multirow{2}{*}{ Carbons } & \multicolumn{4}{|c|}{ Proximate analysis (\%) } & \multicolumn{3}{|c|}{$\begin{array}{c}\text { Ultimate } \\
\text { analysis (\%) }\end{array}$} & \multirow{2}{*}{$\begin{array}{c}\text { Burn } \\
\text { off } \\
\%\end{array}$} & \multirow{2}{*}{$\begin{array}{c}\text { Yield } \\
\%\end{array}$} \\
\hline & $\begin{array}{c}\text { Moisture } \\
\text { content }\end{array}$ & $\begin{array}{l}\text { Volatile } \\
\text { content }\end{array}$ & $\begin{array}{c}\text { Ash } \\
\text { content }\end{array}$ & $\begin{array}{c}\text { Fixed } \\
\text { content }\end{array}$ & C & $\mathbf{H}$ & $\mathbf{N}$ & & \\
\hline TSC600 & $\begin{array}{c}3.60 \pm \\
0.02\end{array}$ & $\begin{array}{c}32.50 \pm \\
0.03\end{array}$ & $\begin{array}{c}28.36 \pm \\
0.02\end{array}$ & $\begin{array}{c}35.54 \pm \\
0.03\end{array}$ & 36.77 & 3.79 & 3.54 & 29 & 71 \\
\hline TSC300 & $\begin{array}{c}2.10 \pm \\
0.00\end{array}$ & $\begin{array}{c}32.15 \pm \\
0.05\end{array}$ & $\begin{array}{c}14.25 \pm \\
0.02\end{array}$ & $\begin{array}{c}49.40 \pm \\
0.03\end{array}$ & 41.9 & 1.24 & 1.08 & 26 & 74 \\
\hline
\end{tabular}

Table 1: Characterization of tannery sludge activated carbons.

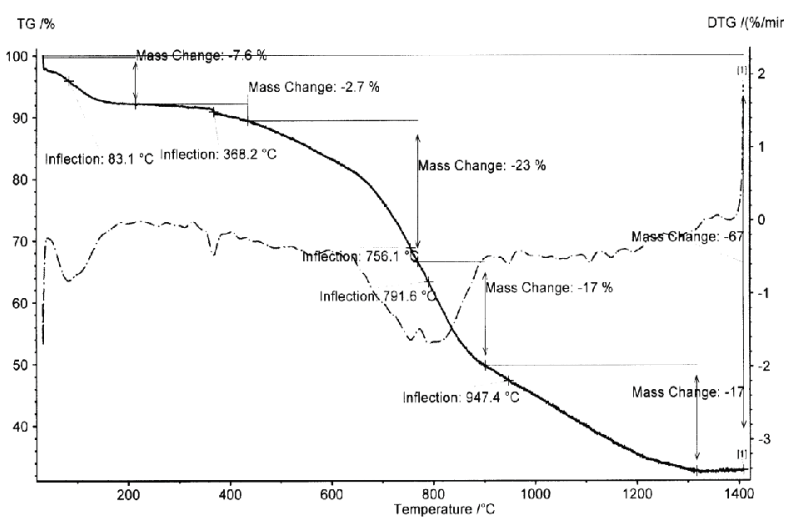

Figure 1: TG curves of tannery sludge activated carbon (SC600).

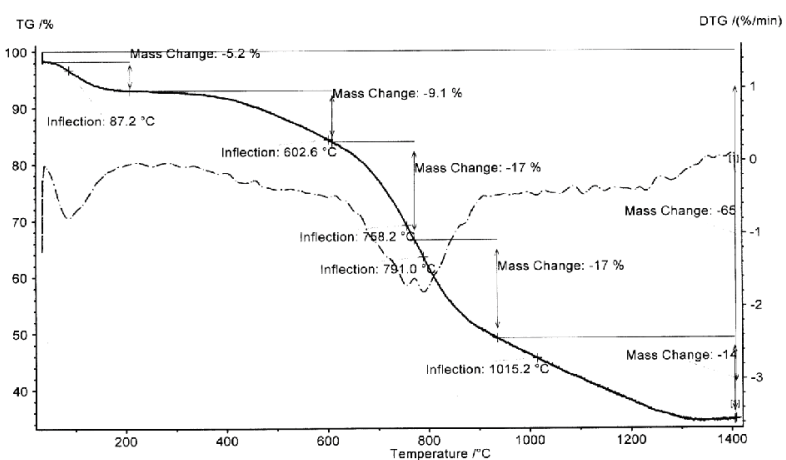

Figure 2: TG curves of tannery sludge activated carbon (SC300).

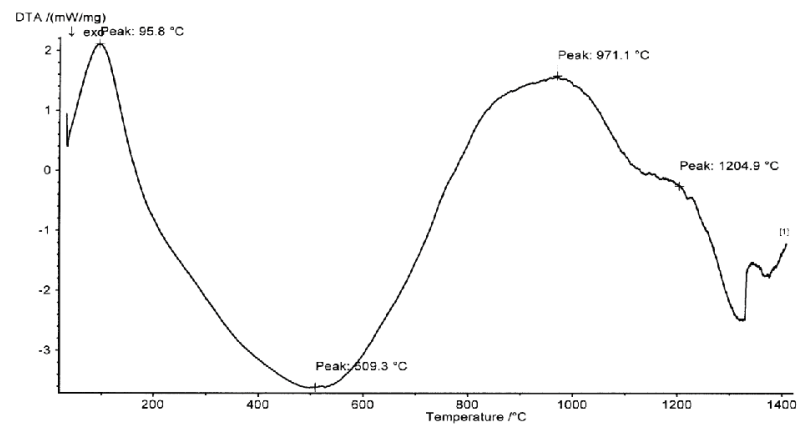

Figure 3: DT curves of tannery sludge activated carbon (SC600).

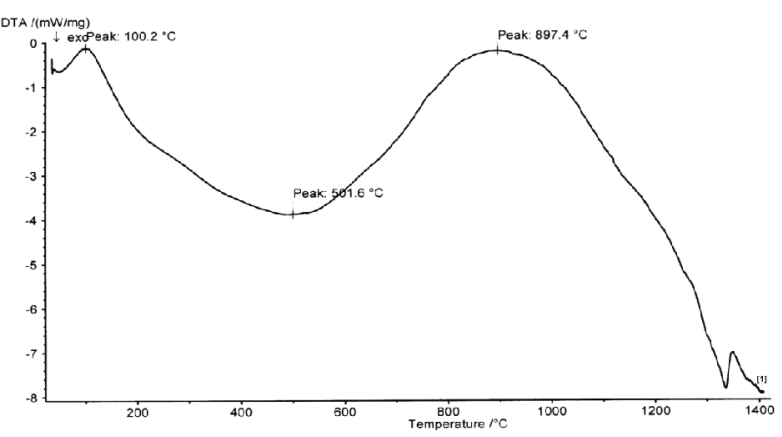

Figure 4: DT curves of tannery sludge activated carbon (SC300).

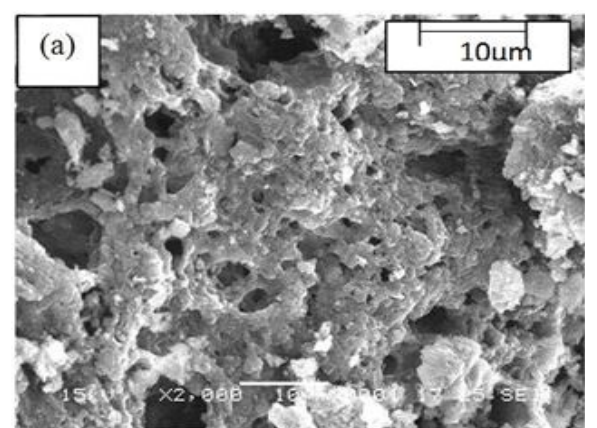

Figure 5a: SEM images of tannery sludge carbon TSC600 activated at $650^{\circ} \mathrm{C}$ respectively.

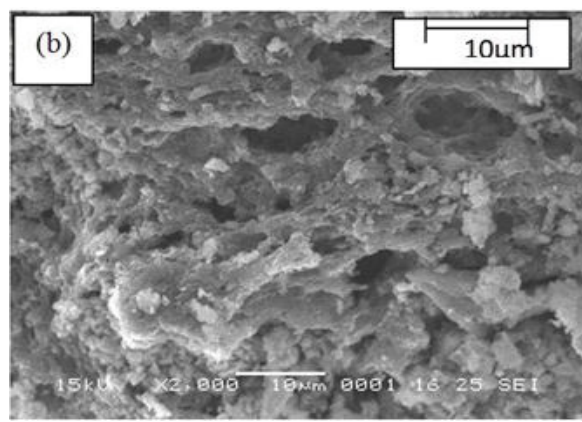

Figure 5b: SEM images of tannery sludge carbon TSC300 activated at $650^{\circ} \mathrm{C}$ respectively.

evaporation of free moisture content. The major weight loss of $23 \%$ and $17 \%$ was observed from the illustrations. This loss was due to the release of the volatile matter with increase in temperature. The exothermic peaks 
observed from the DT curves for TSC600 and TSC300 are shown in Figures 3 and 4 . The thermal stability for sludge carbons were confirmed by its exothermic peak at $971.1^{\circ} \mathrm{C}$ and $894.4^{\circ} \mathrm{C}$ for TSC600 and TSC300 respectively.

SEM analysis: The presence of mesopores and micropores on the external surface of the developed tannery sludge carbon after the combined chemical and physical activation are revealed from the SEM micrographs of the tannery sludge activated carbons (TSC600 and TSC300) and shown in Figures 5a and 5b. The pores were formed due to the release of volatile matters and the reaction between the sulphuric

\begin{tabular}{|c|c|c|c|c|}
\hline Activated & Surface area & Pore volume & \multicolumn{2}{|c|}{ Pore width $\mathbf{( A}^{\circ}$ ) } \\
\cline { 4 - 5 } carbon & $\left(\mathbf{m}^{2} \mathbf{g} \mathbf{)}\right.$ & $\mathbf{( \mathbf { c m } ^ { 3 } / \mathbf { g } )}$ & BJH method & HK method \\
\hline TSC600 & 188.25 & 0.134239 & 19.77 & 5.15 \\
\hline TSC300 & 212.32 & 0.1325 & 19.73 & 5.07 \\
\hline
\end{tabular}

Table 2: Porosity characterisation of the tannery sludge activated carbons by BET isotherm.

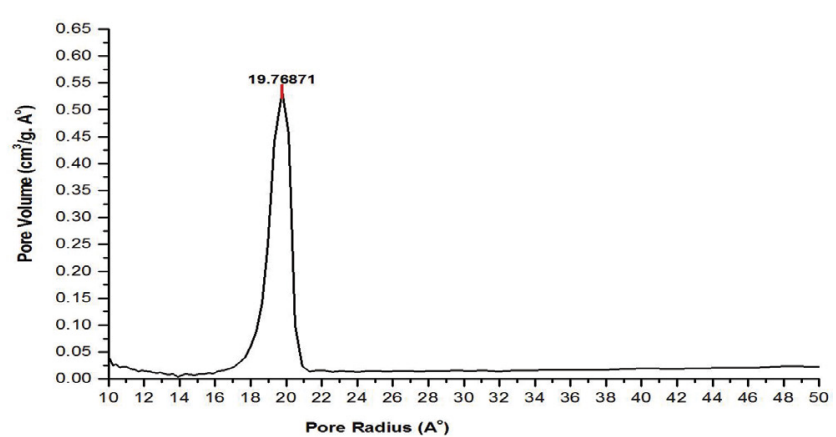

Figure 6a: BJH Desorption Pore Distribution of tannery sludge activated carbon TSC600.

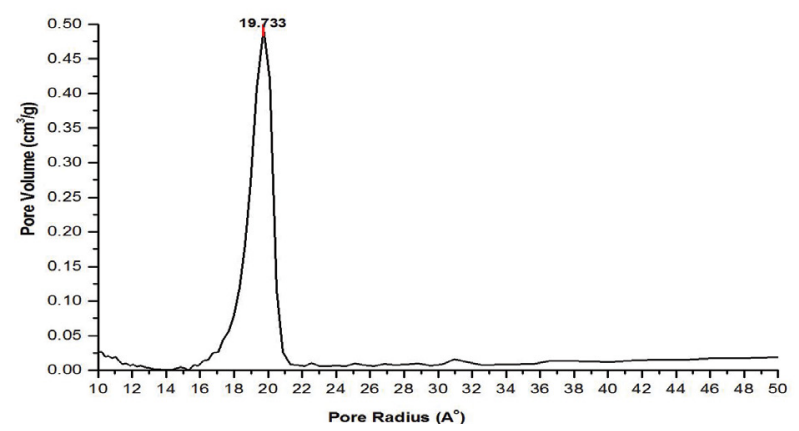

Figure 6b: BJH Desorption Pore Distribution of tannery sludge activated carbon TSC300.

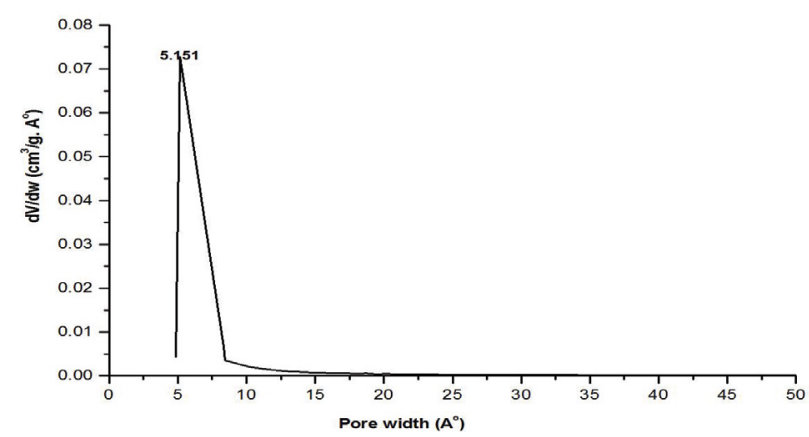

Figure 7a: HK Desorption Pore Distribution of tannery sludge activated carbon TSC600.

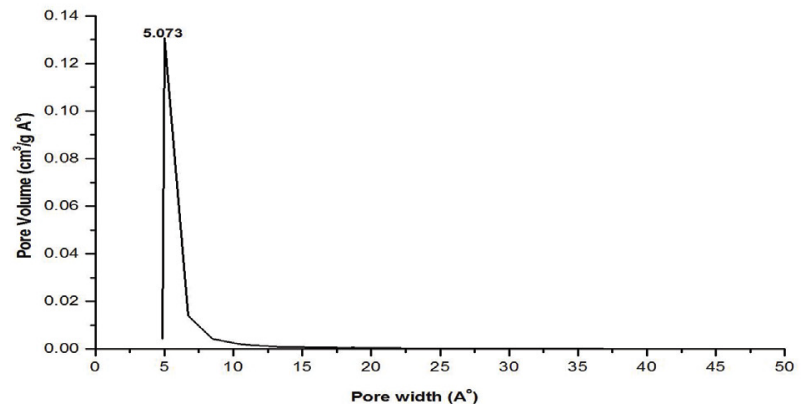

Figure 7b: HK Desorption Pore Distribution of tannery sludge activated carbon TSC300.

\begin{tabular}{|c|c|c|c|c|c|c|}
\hline Adsorbent & Carboxylic & Lactonic & Phenolic & Basic & Acidic & All \\
\hline SC600 & 0.002 & 0.012 & 0.012 & 0.006 & 0.026 & 0.032 \\
\hline SC300 & 0.006 & 0.01 & 0.011 & 0.007 & 0.027 & 0.034 \\
\hline
\end{tabular}

Table 3: Results of Boehm titration in $\mathrm{mmol} / \mathrm{g}$ for various activated carbons.

acid and the carbon atom in the precursor (raw tannery sludge). The pore width was determined from the image with a magnification of $5,000 \mathrm{X}$ by using the appropriate scale of $10 \mu \mathrm{m}$ represented in the image.

BET isotherms: The adsorptive capacity of activated carbon is related to its specific surface area, pore volume and pore size distribution. The porosity characterisation of the tannery sludge activated carbons are shown in Table 2. The surface area of the activated carbon decreased with the particle size of the activated sludge carbon. The pore size distribution of tannery sludge carbons was studied by BJH method and HK method of adsorption isotherm. The surface area of TSC300 was higher than TSC600 and the pore size distribution were dominated and uniformly distributed with mesopores and micropores. From Figures $6 \mathrm{a}$ and $6 \mathrm{~b}$ and Figures $7 \mathrm{a}$ and $7 \mathrm{~b}$ it is clear that the activated carbon produced from the tannery sludge was in the mesopore and micropore range.

Boehm titration: Introduction of functional groups containing oxygen is the major purpose of oxidation. Boehm proposed titrations of carbons with bases of various strengths. According to Boehm titration, the numbers of carboxylic, lactonic, and phenolic groups can be identified. Table 3 presents the Boehm titration results. The number of groups was reported in terms of surface concentration $(\mathrm{mmol} / \mathrm{g})$. For both sludge activated carbons, the number of acidic groups significantly increased with a decrease in the number of basic groups after oxidation [15]. The Boehm titration results revealed that, with increase in the particle size of the sludge carbons, the concentration of acidic and basic groups decreased. Hence lesser the particle size, greater is its surface functional group and quicker is the rate of adsorption of dyes. The acidic functional groups of the carbons were greater than the basic functional groups due to the activation of the carbon using acid as the precursor.

\section{Conclusion}

The combined physical and chemical activation at $650^{\circ} \mathrm{C}$ was found to be optimum in using sulphuric acid as the activating agent. The burnoff of TSC600 and TSC300 were $29 \%$ and $26 \%$ and the yield percentages of the two carbons were $71 \%$ and $74 \%$ respectively. The thermal stability for different activated carbons was confirmed by their exothermic peaks at $971.1^{\circ} \mathrm{C}$ and $897.4^{\circ} \mathrm{C}$ respectively. The SEM images of the activated sludge carbons depicted the pore formation. The combined activation on the sludge has led to the development of micropores and mesopores on the external surface of the carbons. The surface areas of the various carbons were in the order of $\mathrm{S}_{\mathrm{SC} 300}: 212.32 \mathrm{~m}^{2} / \mathrm{g}>\mathrm{S}_{\mathrm{SC} 600}: 188.205 \mathrm{~m}^{2} / \mathrm{g}$ respectively. The pore size distributions were dominated with mesopores 
and micropore were also uniformly distributed. The micropore widths of the activated carbons were $5.15 \mathrm{~A}^{\circ}$ and $5.07 \mathrm{~A}^{\circ}$ and the mesopore widths were $19.77 \mathrm{~A}^{\circ}$ and $19.73 \mathrm{~A}^{\circ}$, respectively. The cationic nature of the developed activated sludge carbons was confirmed by the Boehm titrations methods with higher acidic functional groups.

\section{References}

1. Pereira MFR, Soares SF, Orfao JJM, Figueiredo JL (2003) Adsorption of dyes on activated carbons: Influence of surface chemical groups. Carbon 41: 811-821.

2. Singh KP, Mohan D, Sinha S, Tondon GS, Gosh D (2003) Color removal from wastewater using low-cost activated carbon derived from agricultural waste material. Ind Eng Chem Res 42: 1965-1976.

3. Valdes H, Sanchez-Polo M, Rivera-Utrilla J, Zaror CA (2002) Effect of ozone treatment on surface properties of activated carbon. Langmuir 18:2111-2116.

4. Pelekani C, Snoeyink VL (2001) A kinetic and equilibrium study of competitive adsorption between atrazine and congo red dye on activated carbon: The importance of pore size distribution. Carbon 39: 25-37.

5. Barbooti MM, Mohamed TJ, Hussein AA, Abas FO (2004) Optimization of pyrolysis conditions of scrap tires under inert gas atmosphere. J Anal Appl Pyrolysis 72: 165-170.

6. Zabaniotou AA, Stavropoulos G (2003) Pyrolysis of used automobile tires and residual char utilization. J Anal Appl Pyrolysis 70: 71-72.
7. Al-Degs Y, Khraisheh MAM, Allen SJ, Ahmad MN (2003) Effect of carbon surface chemistry on the removal of reactive dyes from textile effluent. Water Res 34: 927-935.

8. Kaushik P, Malik A (2009) Fungal dye decolourization: Recent advances and future potential. Environ Int 35: 127-141.

9. Suteu D, Bilba D, Mureşan R, Mureşan A (2008) Using fibrous materials for textile wastewaters treatment. Proceedings of $4^{\text {th }}$ International Textile, Clothing and Design Conference- Magic World of Textiles, Dubrovnik, Croatia. pp. 1112-1117.

10. Crini G (2006) Non-conventional low-cost adsorbents for dye removal: A review. Bioresour Technol 97: 1061-1085.

11. Geethakarthi A, Phanikumar BR (2011) Adsorption of two Azo reactive dyes by tannery sludge activated carbon: Effect of temperature and $\mathrm{pH}$, International conference on environmental science and development. 4: 154-157.

12. Murillo R, Navarro MV, Lopez JM, Garcia T, Callen MS, et al. (2004) Activation of pyrolytic tire char with $\mathrm{CO}_{2}$ : Kinetic study. J Anal Appl Pyrolysis 71: 945-957.

13. El-Sheikh AH, Newman AP, Al-Daffaee HK, Phull S, Cresswell N (2004) Characterization of activated carbon prepared from a single cultivar of Jordanian olive stone by chemical and physicochemical techniques. J Anal Appl Pyrolysis 71: 151-164.

14. Boehm HP (1966) Chemical identification of surface groups. Adv Catal 16: 179-274.

15. Salame II, Bandosz TJ (1999) Experimental study of water adsorption on adsorption on activated carbons. Langmuir 15: 587-593. 